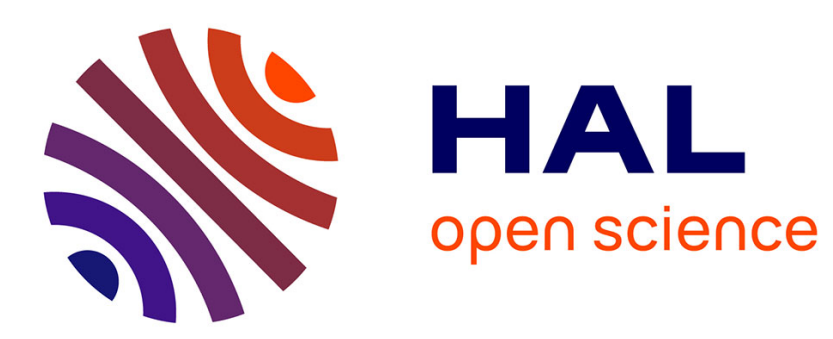

\title{
Main Teleprocessing Monitors for Third-Generation Computers in the USSR
}

\author{
Vladimir A. Kitov
}

\section{To cite this version:}

Vladimir A. Kitov. Main Teleprocessing Monitors for Third-Generation Computers in the USSR. IFIP International Conference on the History of Computing (HC), Sep 2018, Poznan, Poland. pp.127-135, 10.1007/978-3-030-29160-0_8 . hal-02386543

\section{HAL Id: hal-02386543}

\section{https://hal.inria.fr/hal-02386543}

Submitted on 29 Nov 2019

HAL is a multi-disciplinary open access archive for the deposit and dissemination of scientific research documents, whether they are published or not. The documents may come from teaching and research institutions in France or abroad, or from public or private research centers.
L'archive ouverte pluridisciplinaire HAL, est destinée au dépôt et à la diffusion de documents scientifiques de niveau recherche, publiés ou non, émanant des établissements d'enseignement et de recherche français ou étrangers, des laboratoires publics ou privés. 


\title{
Main Teleprocessing Monitors for Third-Generation Computers in the USSR
}

\author{
Vladimir A. Kitov ${ }^{1(\mathbb{} ه)}$ \\ ${ }^{1}$ Plekhanov Russian University of Economics, Stremyanny per., 36 Moscow, Russia \\ vladimir.kitov@mail.ru
}

\begin{abstract}
In the 1970s and 1980s, one of the main directions of the development of system software for computers of the third generation was the creation of multi-terminal software complexes that provided interactions of many users of remote terminals with a central computer in the real-time mode. These software complexes (systems) were known under common name teleprocessing monitors (or telemonitors). A teleprocessing monitor (also, transaction processing monitor or TP monitor) is a control program that monitors the transfer of data between multiple local and remote terminals to ensure that the transaction processes complete [1]. This article describes these teleprocessing monitors of the third-generation computers used in the USSR such as OB, PRIMUS, CICS, KAMA and DRIVER. The most popular of these, though, was the original Soviet telemonitor ОВ (ОБЬ in Russian). ОВ was created in the secret scientific research institute "Monolith" (Secret Number R-6211) of the Ministry of Defense Industry of the USSR by a group of programmers led by the author of the present article V. A. Kitov. This article is based on the work of computer scientists, the analysis of technical documentation, the personal memories and archive of the author and his colleagues. In the 1970s-1980s, the ES EVM computers were the main computers in the USSR.

The story of this development complicates the notion that the USSR simply borrowed architecture and software from IBM and other IT-companies in the 1970s and 1980s. In fact, adapting these systems for Soviet purposes proved to be frustrating, so innovation resulted. The development of OB shows a high level of Soviet programmers at the end of the cold war. OB was a large software package with over a million lines of code.

Therefore, the history of the creation and use in the USSR of system software telemonitors is an important part of the history of Soviet computers, on the one hand, and important part of the world history of system software telemonitors, on the other hand. How pointed at [14] "CICS generated over $\$ 60$ billion in new hardware revenue for IBM, and became their most-successful mainframe software product." Soviet programmers created their own original telemonitor OB, which played a similar role as telemonitor CICS. In the Soviet Union more than 40 percent of Soviet ES EVM computers used this telemonitor OB.

The experience of creation and practical use of the telemonitor OB was also important after the end of use of the third-generation computers in the USSR and in the world (in the USSR they were ES EVM computers). In the 1990s, the architectural solutions of the software of telemonitor OB were the basis for creation
\end{abstract}


of the Russian system BAIKONUR for new computers of the next generation: RISC-servers.

Keywords: AN2 • BAIKONUR • CICS • ES EVM • IBM System/360 • KAMA $\bullet$ OB $\bullet$ On-Line Mode $\bullet$ PRIMUS $\bullet$ Real-Time Software $\bullet$ Teleprocessing Monitor $\bullet$ Telemonitor $\bullet$ Time Sharing.

\section{Introduction}

The article is devoted to the history of the most popular in the USSR telemonitors for third-generation computers (mainframes IBM/360 and its analogs in the world). Soviet and Western telemonitors such as OB, PRIMUS, CICS, KAMA and DRIVER are considered. Computers of the third generation were the major computers in the world for almost 25 years. An important part of the history of these computers is the history of the creation and use of software teleprocessing monitors, which is not yet well covered. This article is the first to cover the pages of the history of teleprocessing monitors used in the USSR. The creation in the USSR of two own advanced telemonitors OB and PRIMUS refutes the opinion of some historians of science that in the period 1970-1980 there was no original development in the USSR. The article clearly demonstrates the fact that in the USSR in the 1980s, the telemonitor OB was created at the world level of software, which perfectly controlled all huge quantity of types of terminals used in the USSR and provided machine-to-machine exchange between remote computers. It was not yet the Internet, but it was important for concrete data exchange between computers in practice - for example, between the computers of the main computing centers of nine weapon ministries in the USSR.

Initially, users of the first of the third-generation computers handed their sets of punched cards to a special department of operators, where all these sets were combined into a single package of punch cards, which was uploaded by operators for execution on a computer. The resulting data of the user's tasks were printed as a single array of printouts on alphanumeric computer printers. After that, the received printouts were divided by computer operators into separate paper blocks and issued to each user, respectively. The technology of each user's delivery of their set of punched cards to computer operators and getting their printouts from them with the results of their execution on computer had serious drawbacks. First of all, this was a significant slowdown in the overall process of data processing on a computer. The detection of even an insignificant error in the program forced the programmer to give the newly corrected punched cards to the operator's service one more, which led to extremely low speed of obtaining the results. As a result, there was a significant slowdown in making managerial decisions. The batch mode of data processing deprived managers of the possibility of making decisions in real time, i.e., directly in the process of computer data processing.

The realization that the batch processing mode was a strong brake on the effective use of third-generation computers led to the fact that in the developed countries one of the main directions of their improvement was the creation of telemonitors - teleprocessing monitors (also, transaction processing monitors or TPMs). 
The teleprocessing monitor was the very important part of the system software of the third generation computer and ensured the work of many remote terminal users with the databases of each computer. Telemonitors made it possible to work with remote terminals in real time in the process of solving the tasks performed by the computer. In the USSR the most popular books about real-time systems were [2], [3] and [4]. The article is based on the author's personal experience in using telemonitors CICS, KAMA, DRIVER, PRIMUS and in creating by him and his team the telemonitor OB, as well as on the memories of his colleagues.

\section{Creating and Using the First Telemonitors}

At the first stage of creating telemonitors, system software was designed to display ready-made videograms (pre-prepared reference forms). It was the display on the screens of remote terminals of reference information, prepared in advance. The further operation of system telemonitors in management activities became a real factor of significant growth in the efficiency of enterprise management; more informed decisions were made and the quality of each employee's work activity was improved.

The basic functions of telemonitors for third-generation computers were the following: implementation of control and coordination processes of terminals and communication equipment for network interaction of remote computers; control functions of input-output messages from remote terminals and their editing; ensuring parallel processing and transfer of data; identification of errors in transmitted messages and their correction; dispatching queues of transmitted messages. In the third-generation computer, the specified functions for controlling the operation of the terminals were performed by a software complex included in the system software, called a telemonitor.

Starting in 1970, the world's leading computer companies started to develop their own telemonitors in addition to their batch operating systems (OS). In particular, the world giant IBM created a CICS telemonitor for their IBM/360 computers. British ICL corporation for its ICL System 4 computers developed a DRIVER telemonitor. In the Soviet Union, on the first ES EV models of computers on which IBM's borrowed system software was installed, a KAMA telemonitor was used, a copy of the IBM CICS telemonitor [6-10].

Later, two teams of Soviet programmers for Soviet ES EVM computers developed their original OB and PRIMUS telemonitors. Both telemonitors received good reviews from users of the ES EVM computers. The OB telemonitor became very popular and was widely implemented to provide users of thousands of different Soviet information management systems real-time [3-5].

\section{System Telemonitors CICS (IBM, USA) and KAMA (USSR)}

In the middle of 1969, the CICS program for the IBM System/360 computers became the world's first industrially used telemonitor. CICS provided an interactive mode of interaction of the computer with users of remote terminals and computers among themselves. For the first ES EVM computers, which were first released in 1969, the system 
software was illegally taken from IBM. The Soviet telemonitor KAMA for ES EVM was a direct "copy" of the American CICS. KAMA accurately repeated all the functions of CICS.

Unlike batch mode operation, an abnormal task termination in the KAMA (CICS) memory section resulted, on the one hand, in violation of the normal functioning of the system and in the loss of some of the data entered from the terminals, on the other. To resume the work of this telemonitor, it was necessary to restart it, which was its significant drawback. The working environment of the KAMA telemonitor included terminals, data sets, query queues, application programs and transactions.

Projects with KAMA telemonitors for creating software and technical complexes for data exchange between remote computers demonstrated the need for coordinating data between computer systems. In particular, in the second half of the 1970s in the Ministry of the Merchant Marine of the USSR (MinMorFlot), two such projects were implemented by the team of programmers from the Ministry's computer center under the leadership of V. A. Kitov (the present author). The first project was the creation of a multi-computers complex data exchange between the ES EVM computer (central database computer), the French computer SINTRA (computers switching communications with remote computers and terminals) and ES EVM computers installed in all sixteen shipping companies of the country. In this project, KAMA acted as a telemonitor for the central computer ES EVM. As a result, the delivery of real-time data to the MinMorFlot staff from all the shipping companies of this ministry located in all sea areas of the USSR from Kamchatka to the Baltic republics was achieved.

The same team of programmers developed a second project based on the KAMA telemonitor. It was a software package that provided data processing in the Soviet satellite rescue system for ships and airplanes COSPAS (KOCПAC in Russian), which was part of the international rescue complex KOSPAS-SARSAT. In the COSPAS system, the main task of KAMA was to ensure the delivery of operational information to rescue personnel. Every plane and every ship had a radio beacon. This radio beacon began to transmit the coordinates of its location in the event of an accident. As a result, the ministry in Moscow obtained the location (coordinates) of the vessel or aircraft that had suffered the accident. The central ministry computer immediately located the rescue means closest to the accident (for example, other nearby vessels) and informed the rescue personnel who had issued instructions for assistance. This project was created by the USSR, the U.S., Canada, and France.

\section{The System Telemonitor DRIVER (ICL, UK)}

In 1972, the Main Computer Center of the State Planning Committee of the USSR purchased terminal equipment for two of its powerful computers at that time, ICL System 4-70s. To enable the use of remote terminals, ICL had created its own telemonitor, called DRIVER. It had the same similar problems like CICS or KAMA. The head of the Main Computer Center ordered the present author, system programmer Vladimir Kitov, to learn DRIVER. The ease of use of the DRIVER telemonitor allowed Kitov to 
create a simple information system for interactive interaction of users of remote terminals with a computer ICL System 4-70 in just two months. These users were the specialists of data preparation department. Two more months it took Kitov to create, on the basis of the telemonitor DRIVER, the software system TSO: a system for debugging programs in real-time mode.

The British telemonitor DRIVER was successfully used in the five important organizations of the USSR: Computer Center of Vneshtorg, Computer Center of AZLK factory, the Main Computer Center of Gossnab of the USSR, the Main Computer Center of the USSR State Planning Committee, Scientific Institute of Management Problems of AS of the USSR.

\section{The System Telemonitor PRIMUS (USSR)}

During this time, the architecture and software of the Soviet ES EVM, which had begun as a clone of IBM System/360, increased in complexity. Soviet computer scientists struggled to adapt the American software systems like CICS, CRJE and TSO to the Soviet computers. The moment came when it became clear to the specialists that the Soviet ES EVM computers needed their own telemonitor, one that would take into account all the features of the new models of the ES EVM computers and a very large quantity of types of its terminals. New models of ES EVM computers and new types of Soviet terminal equipment had new standards. And Western software was no longer compatible with these new standards. One of the first national-scale telemonitors of domestic design was the collective access system, called PRIMUS. The main goal of PRIMUS was the remote access of terminal users to databases of the central computer. The first version of the PRIMUS telemonitor appeared in the second half of the 1970s. In the years that followed, this system was gaining increasing popularity in the country for the ES EVM computer. This set the stage for a further development in this area. PRIMUS was a very important step for Soviet informatics because PRIMUS was the first domestic teleprocessing monitor.

\section{The System Telemonitor OB (USSR)}

In the USSR, the most widespread system telemonitor was the telemonitor OB, the full name of which sounded as the Multi-Terminal System for Distributed Data Processing OB (OБB in Russian). Although development of OB did not start until 1980, by the second half of the 1980s, OB was used on more than $40 \%$ of all ES EVM computers of the USSR. At this time, the author of this article worked as head of the real-time data processing software department at the secret Central Scientific Research Institute "Monolith" (secret index R-6211), the main institute of informatics of the Ministry of Defense Industry of the USSR. As a result of the previous eight-year experience in creating interactive software systems, he had a strong opinion that in the Soviet Union an original Russian telemonitor was needed. The new telemonitor would have to satisfy all the requirements for the creation and operation of computer information systems for thousands of enterprises in the country. This was primarily the provision of computer 
systems that support the simultaneous operation of hundreds remote terminals, the operation of branched network systems of intercomputer interaction, a built-in interactive debugging program, a developed package of service programs, and a well-developed library of standard applied dialog programs. Nevertheless, the creators imagined a distributed computing environment for users who had little expertise in computers but could benefit from the addition of computing power to their work life. OB was a large software package with over a million lines of code.

OB developers did not have a task to create any computer network like NSFNET or others. They had the task to create the program system for managing the multi-terminal networks on each of many enterprises of the USSR.

The creation of the OB was preceded by a period of study of the corresponding theoretical basis and practical use of foreign and Soviet predecessors of $\mathrm{OB}$ - telemonitors CICS, KAMA, DRIVER and PRIMUS. During this time, their shortcomings and inconveniences of use were revealed, so an extensive list of necessary improvements was easy to form. As a result, a team of programmers of the software department of the STD of the Central Research Institute "Monolith" created the original Russian telemonitor $\mathrm{OB}$. The initiator and head of the OB system project was the present author. Leading developers were talented system programmers Vladimir Dyakonov and Igor Kalinchev. The first version of the telemonitor OB appeared at 1981. From the very beginning, OB was created to manage heterogeneous multi-terminal networks and to ensure the functioning of computer networks.

The creators of the telemonitor "OB" (in Russian $O Б b$ ) gave it a name with the Russian letter "b," which exists only in the Russian alphabet. This choice stressed the originality of their software. At that time, the Russian character clearly indicated the absence of any foreign analogues in the new software package. It is not a secret that a number of well-known Soviet systems and application programs for the first models of ES EVM were simply borrowed from IBM. Soviet officials did not inform Soviet society about it and the KGB's involvement in this deal. In these borrowed software packages, these allegedly Soviet programs had in their names only those Russian letters that had the same English letters (for example, A, K, M, O, T, etc.). In addition, for the ease of replacing English names in Soviet analogue programs with Russian ones, these programs also had the same number of letters in the title as their American prototypes. For example, Soviet programs KAMA and OKA are the American programs CICS and IMS. KAMA, OKA, and OB (ОБЬ) were three large Soviet software complexes for ES EVM computers. They were named in honor of the three famous rivers of Russia. However, only OB was fully developed in Russia. The telemonitor KAMA was taken from IBM (telemonitor CICS). DBMS OKA is a Soviet adaptation of the American software system IMS.

The telemonitor OB had several important advantages. In addition to its own interface, the OB supported standard telecommunication access methods (protocols) of the BTMD and OTMD of the ES EVM computers and a huge terminal park - several dozen types of terminal devices. As already mentioned, $\mathrm{OB}$ was widely distributed in the USSR, where more than forty percent of all ES EVM computers operated under its control, while under IBM CICS, no more than fifteen percent of all ES EVM computers in the country operated. Being significantly less resource-intensive than foreign CICS, 
the OB had a more user-friendly interface and supported many other types of terminals, including personal computers (PCs). It is logical that some Western telemonitors supported PCs as well. The development of OB demonstrates the high development of computer research in the 1980s in the USSR, which used systems of inter computer data exchange. On the example of the telemonitor OB, it can be seen that in the 1980s, Soviet programmers were at least on same level with Western programmers.

In the creation of the telemonitor $\mathrm{OB}$, the leading role was played by a remarkable team of software developers (first of all, Dr. Vladimir Dyakonov, Dr. Igor Kalinchev, Dr. Igor Zhitenyov and Dr. Vladimir Denisenko) of the department of the real-time software of the Research Institute "Monolith" of the Ministry of Defense Industry of the USSR, headed by Dr. Vladimir Kitov. In the course of eight years of its existence, this department created and successfully used the famous large-program systems at over two hundred enterprises only of the Ministry of Defense Industry of the USSR. These are LISTER, for prompt information management; KDOM, for interactive debugging; the intercomputer data exchange between nine Computer Centers of Defense Ministries of the USSR; two complexes of programs for checking information on disk volumes (PDT) and tape volumes (PLT); FORMATOR, for computer analysis and data preparation for storage in DBMS; TERMES, for viewing and updating information in consecutive files in dialog mode; CONTROL, the dialogue system of execution of instructions and documents; the telemonitor OB, and others. In the middle of 1980s, OB was successfully approved by the State Commission of the USSR and included to the Soviet export fund "Center Program System" (All-Union Fund of Algorithms and Programs) for wide distribution at the enterprises of the USSR and abroad.

\section{$7 \quad$ OB's Second Life}

Unlike the vast majority of ES EVM software systems, the OB telemonitor did not come off the stage in the era of personal computers (PCs). In 1996, the telemonitor OB experienced a second birth when the Russian company Epsilon Technologies used the architectural design and functionality of the $\mathrm{OB}$ telemonitor as the basis for the new software package BAIKONUR.

BAIKONUR was designed to work on next-generation computers: RISC servers. Then, the company Epsilon Technologies took advantage of the experience of highly qualified programmers from the defense research institute "Monolith" and the Academy of Sciences of the USSR. Thanks to this, based on the ideas and experience of the development of the telemonitor OB, the new software complex mentioned above was born. The most difficult task of the initial stage of its creation, according to Andrey Chesnokov, the head of the BAIKONUR project, was the creation of a well-coordinated team of developers from the old school of system programmers and Borland-style programmers of the new generation. It is the fusion of the programmers of the "old school," brought up in the tradition of multi-tasking and well-structured operating systems of IBM's and ES EVM's mainframes, with developers accustomed to RAD-tools, allowed to combine the convenience of application development and high performance inherent in the BAIKONUR system [11, 12]. Today, the ideas outlined in the creation of large 
Soviet and Russian software complexes OB and BAIKONUR find further fruitful development in the new projects of the next generation of Russian programmers.

\section{Conclusion}

In the article for the first time in the historical literature the review of the main system telemonitors used in the USSR for computers of the third generation is done. The leading role of domestic telemonitors is shown. For Soviet computers, the telemonitor OB had significant advantages over similar Western systems. OB was used on forty percent of the total number of ES EVM computers operated in the USSR. By 1990, ES EVM had already ceased to be the main computers in the country. Their positions were replaced by personal computers and next-generation servers. The experience of the creating a purely domestic telemonitor $\mathrm{OB}$, consisting of several hundred thousand computer instructions, was useful even after computers ES EVM leaving the scene. In particular, these were good software architecture ideas and a wealth of programmer experience. The telemonitor $\mathrm{OB}$ formed the basis for the next generation software package BAIKONUR (Project Manager Andrey Chesnokov). OB is the typical example of the large software complexes created by the Soviet programmers.

The article uses information from books on data teleprocessing [2-3], technical documentation on CICS, KAMA, DRIVER, PRIMUS and OB (ОБЬ) telemonitors [7-11], books and articles by the author and his colleagues [4-6], and works devoted to the systems BAIKONUR [12-13].

\section{References}

1. Teleprocessing monitor// https://en.wikipedia.org/wiki/Teleprocessing_monitor, last accessed 2019/31/03

2. Blackman M.: Projecting of real-time systems. MIR, pp. 29-314, Moscow (1977).

3. Sipser R. Architecture of communication in distributed systems. Mir, p. 661, Moscow (1981).

4. Dyakonov V. Yu., Kalinchev I. A., Kitov V.A.: Software of data teleprocessing systems. "SCIENCE" publishing house. (Main edition of physical and mathematical literature. Series "The Library of the Programmer"), 165 p., Moscow (1992).

5. Dyakonov V. Yu., Kalinchev I.A., Kitov V.A. The principle of software mobility of multiterminal distributed data processing systems // Programming. 1984. № 2.- P. 46-53.

6. Dyakonov V. Yu., Kalinchev I. A., Kitov V. A. Multiterminal system for distributed data processing OB. // "Computer technology of the socialist countries." Moscow: Finance and Statistics, 1987. Issue. 22. P. 131-136.

7. Customer Information Control System (CICS) General Information Manual (PDF). White Plains, New York: IBM. December 1972. GH20-1028-3. Retrieved 2016-04-01.

8. Transaction Processing Monitor http://wiki.c2.com/?TransactionProcessingMonitor

9. IBM Corporation (1972). Customer Information Control System (CICS) Application Programmer's Reference Manual (PDF). Retrieved Jan 4, 2016.

10. “CICS - An Introduction" (PDF). IBM Corporation. July 8, 2004. Retrieved April 20, 2014. 
11. "Customer Information Control System/Virtual Machine (CICS/VM)". IBM. October 20, 1987. Retrieved 2016-04-02.

12. Intel Has Put Baikonur "Very Good" Rating // CRN, \# 13 (48) of 17.071998 https://www.crn.ru/numbers/reg-numbers/detail.php?ID=3367

13. Baikonur Web Application Server - client-server architecture for Intranet-based access to corporate databases // CIT Forum: http://citforum.ru/programming/application/baiconur.shtml, last accessed 2019/31/03.

14. CICS // https://en.wikipedia.org/wiki/CICS. last accessed 2019/31/03. 